\title{
Money and Marriage: A Spending Plan ${ }^{1}$
}

\author{
Josephine Turner, Nayda I. Torres, and Vervil Mitchell ${ }^{2}$
}

You probably hear a great deal about how some families struggle to make ends meet. Money concerns are not restricted to just young couples or those with limited funds.

Families have to make some decision about how they want to live and how they want to spend or use their resources, such as time, energy, interests, abilities and money. In other words, you can decide what you want your lifestyle to be. You might want your surroundings to be pleasant and as comfortable as possible. Because this is important, you will spend your time, energy, and money on your home and its

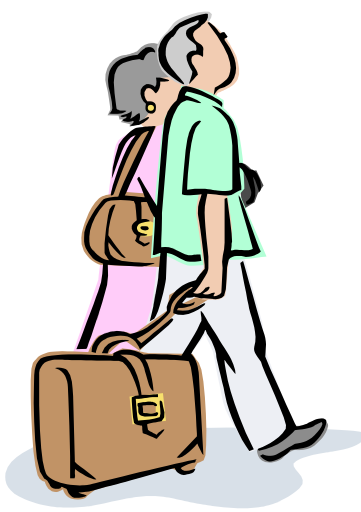

furnishings. Another family might decide that travel is more important, so they may not spend as many of their resources on their home as you. You are both right, but just want different lifestyles. Talk over what you want and what you expect with your family members to prevent money problems.

\section{Plan for Wise Money Management}

Give careful attention to earning, investing, saving, and spending money. What you do in each area affects the others. This sounds simple, but it requires planning for what you want to achieve in each area. It is not easy to keep that plan in the foreground and always control the plan. Financial success is not so much earning money as it is making wise choices about how to use money.

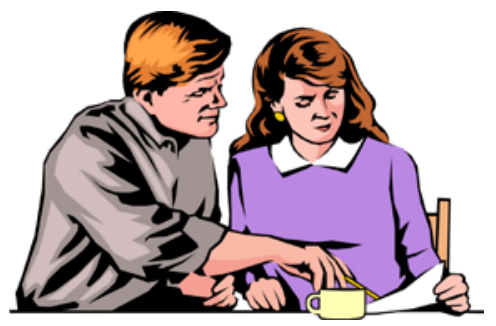

\section{Plan Your Future Now}

Imagine yourself 20 years from now. Where do you expect to be on the economic ladder? What comforts do you want for yourself and your family? What do you want your economic and financial situation to be next year, five years from now; twenty years from now?

The family's financial plan includes general plans and expectations throughout the family's lifecycle. This includes planning for children (or not, as the case may be), educating the children,

1. This document is Fact Sheet FCS7012, one in a series of the Department of Family, Youth and Community Sciences, Florida Cooperative Extension Service, Institute of Food and Agricultural Sciences, University of Florida, Gainesville, FL 32611. Publication date: November 1987. Revised December 2008. Please visit the EDIS Website at http://edis.ifas.ufl.edu

2. Written by Nayda I. Torres, Professor and Chair, Family and Consumer Economics, and Vervil Mitchell, former Family Economics Specialist; revised by Josephine Turner, CFP, Professor, Family and Consumer Economics, and Michael Gutter, Assistant Professor, Department of Family, Youth and Community Sciences, Institute of Food and Agricultural Sciences, University of Florida, Gainesville, FL 32611. 
and earning an income with the occupation of your choice. The plan also involves the family's standard of living, saving, and investment habits, and contributions to others. Your financial plan should be in general terms and cover a long time period, and include a means for making changes throughout the lifecycle.

\section{Agree on Family Goals}

Before you can actually make a spending plan, better known as a budget, you must agree on some goals. You need to establish some shortterm goals, and some for the future, perhaps five to ten years from now.

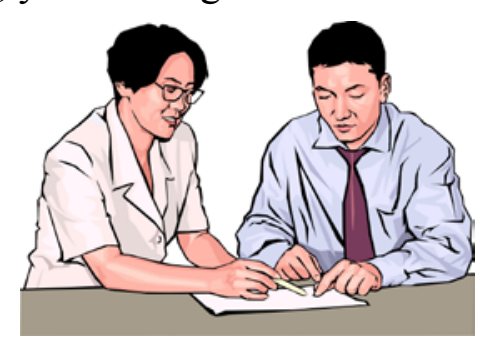

Try to be realistic and agreeable about your goals. Try creating SMART goals. This means you are sure, you both want the "good things in life" right now, but those things come over a lifetime. If you find that your goals are moving in opposite directions, for example, one of you is dreaming about a sleek automobile and the other is determined to pay off a debt, you better bring these aspirations out in the open.

The more specific you are about your short-term and long-term goals, the better. Three questions to go over are what, when, and how much? One goal could be to live comfortably. Other goals might be to start saving for a better car or to buy a chest of drawers. A five-year goal might be to save for a down payment on a house or to begin a family.

Time does not stand still, as a young central Florida couple recently discovered. When they looked back on five years of marriage, they

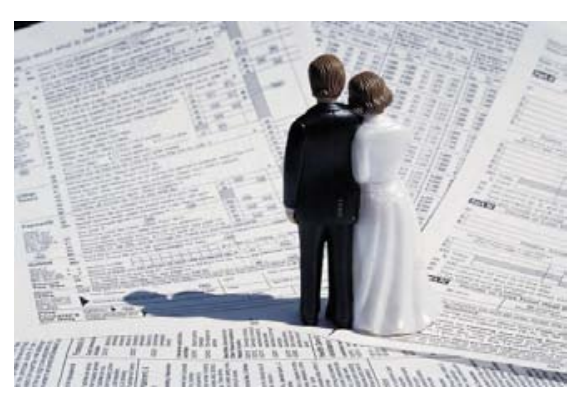
suddenly realized that they were in almost the same economic position as they were when they married. Why? They had never made any definite financial plans for the future.

Without deciding what was important to them or what they wanted, they had just drifted along without any real progress.

Happiness involves controlling your money to get what you want. You can make your money go where you want it to go if you plan ahead.

\section{Establish a Spending Plan}

A spending plan is a money guide to make your money go where you want it to go. A family spending plan is a smart way to make your dollars buy what you most need and want. You can master the skills of money control and learn to conserve your income by using knowledgeable spending. Planning will help you extend your buying power. Good spending habits foster financial security and develop wise use of credit.

No ready-made spending plan fits every couple, or even one couple necessarily. A standard table designating what percentage of income to allow for each budget category cannot be calculated. Each family has different standards, values, needs, wants and resources, so you must decide what percentage to budget for the various categories. For example, if you are a couple who enjoys entertaining at home and wants space, serving equipment, and a generous budget for food, then your particular plan might provide a large portion of your income for these budget categories and less for other groups.

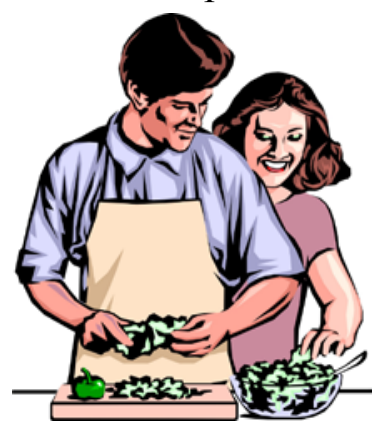

If you are "car conscious" and need a late model car in your line of work, or you like to travel, you may choose to provide a larger transportation allowance and pay less for housing. You may be "clothes conscious" and allocate a larger sum for clothes in order to dress stylishly. 
What you need is a practical spending plan that fits your family. No his and her arrangement here, even if there is a double income. This is supposed to be a money partnership. Joint accounts may help this transition.

Keep the following steps in mind as you begin to establish a sound spending plan:

\section{Step 1: Where are You Financially?}

To find out where you are, add up all your resources. Resources are things such as time, energy and money; they can be used in different ways to fill your needs and achieve your goals. If you want to save money, you can use your own time and energy to get what you want. Or if you want to save time and energy, you can use money. Your resources are interchangeable, but not unlimited. Try to determine the value and amount of these resources available for your use. If time is more important to you than money, then you might buy products such as pre-cooked foods, and purchase services such as yard care.

Money resources may include salaries, interest on bank accounts, rental incomes, gifts, inheritance, bonuses, commissions and unemployment compensation. No one has all these kinds of income, but almost

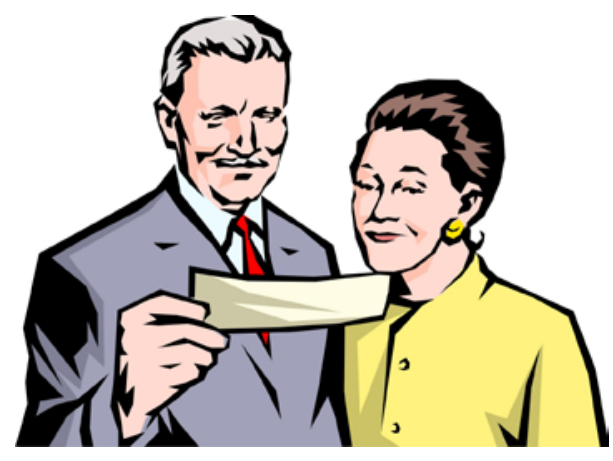
everyone has at least one of these. Add together the ones you have to find out your whole income for a month.

Next determine your amount of spending. Subtract your total expenses from your total income. If there is money left, this is your surplus. If this is negative, this is the amount of your deficit. A second measure is net worth.
Add up everything that you own, these are your assets. Add up everything that you owe, these are your liabilities. Assets minus liabilities is how you determine net worth.

\section{Step 2: What are Your Fixed Expenses?}

These are the recurring expenses you have promised to pay on specific dates and in specific amounts. You might have signed a contract and are bound to pay. Some are monthly, like rent or mortgage, utilities and installment debts. Some occur less often, like insurance premiums, property taxes, license plates and school tuition.

Do not overlook savings as fixed expense. You might have an emergency fund for the

unexpected - car repairs, an accident or an illness. Another area for a special savings account is for goals you are working toward, such as a new car and/or providing

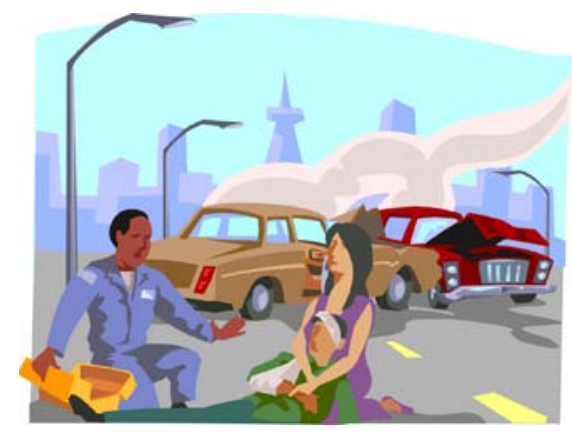
funds for your children's college education. A separate savings account for each lets you see your progress toward your goals. Even $\$ 5$ or $\$ 10$ a month would be a good start toward building a fund. Then when the inevitable happens, you will be able to handle the emergency more easily.

Total your fixed expenses on an annual basis. Subtract that from your annual take-home income. As you can see, the more you have committed to fixed expenses, especially credit bills, the more strapped you are financially.

\section{Step 3: What are Your Flexible Expenses?}

These are expenses that vary from week to week or month to month. Since you are not committed to previous agreements with others, you have 
the most control over these expenses. When you are squeezed financially, you can cut back or even cut some out. Flexible expenses include food, clothing, gifts, transportation, contributions, personal care and entertainment. It is a little harder to figure your past spending

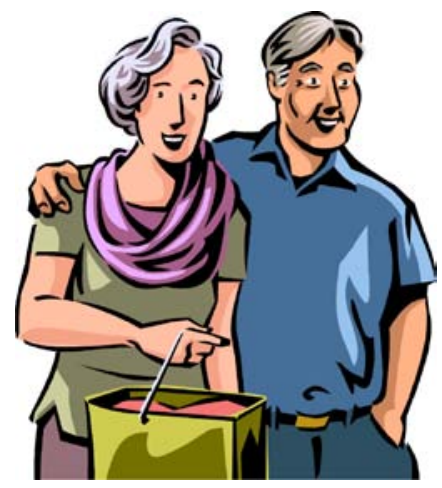
in these areas if you have not kept receipts. Estimate the costs for expenses you do not have records for, or keep track of them for a month or two before you complete this part of the budget.

An important, additional consideration in this category is inflation. When planning ahead, add a percentage increase for inflation. It is hard to know what inflation rate to expect and it will vary for different times. Based on recent years 3 to 6 percent inflation rate would be a safe guess.

Now add up your flexible expenses on an annual basis. Then add the inflation factor.

\section{Step 4: How Can You Balance Expenses?}

Compare the total for flexible expenses with the amount remaining after fixed or committed expenses have been subtracted from your total income. If you have plenty, you are lucky and can move ahead with financial goals. If you do not have enough to cover the estimated flexible expenses, some trimming of expenditures is needed.

Here are some guides:

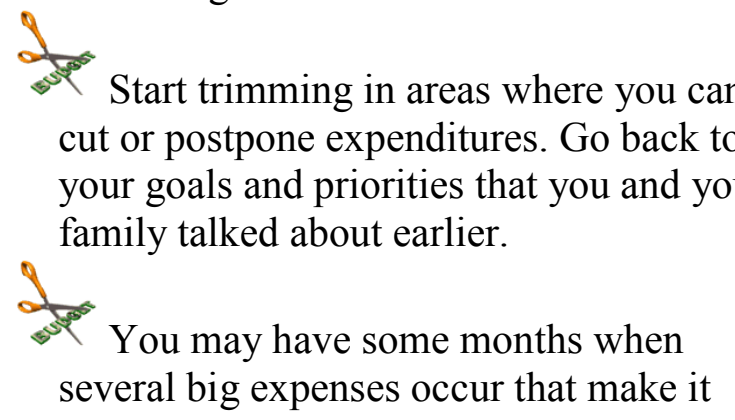

difficult, if not impossible, to pay them. A solution is to take a look at the year and arrange payment dates, such as various insurance premiums, opposite months with expenses you cannot alter, such as property and income taxes.

1

One way to save on insurance premiums is to pay them less often. For example, you can save a significant amount by paying a lump sum annually instead of spreading the payment out. This means planning ahead and saving regularly as you have the money, or paying ahead of the payment due date.

I

Taking a larger deduction on your insurance policy is also a way of reducing the premium. However, in exchange you will need to save and have in your emergency fund the amount of the I deductible in case you need to pay it.

Another means of balancing is to find ways of getting additional income.

\section{Step 5: How Do You Use the New Spending Plan?}

Once you have your future expenses and income balanced, try out your plan. It is important to be flexible, since no plan is perfect. Here are some tips to make your plan successful:

Put it in writing and keep it simple.

Stick to major categories. You can be more specific after you try your plan, or you may decide you want fewer details after getting some experience.

Review the plan and make changes to fit your situation.

Set up a family business center, or a specific place for your financial records. 
No one is born with the ability to manage money: it has to be learned. Experience develops expertise. The secret of having something to show for your hard-earned dollars involves planning and using your money to obtain what you want.

As goals are accomplished, you will need to review and revise your financial plans. The key is still in making joint decisions with the family. Whether you are planning your goals or recording your expenses, everyone who spends the family income should cooperate in adjusting the spending plan to your changing lifestyle.

An easy way to make your spending plan work for the whole family is to include a small allowance for each person. This will give everyone a little freedom to buy on impulse without damaging the budget. It can encourage everyone to work toward the family goals together. Remember that it is not your money and my money, but our money, and it is all the family's resources and skills combined that will make the most of the

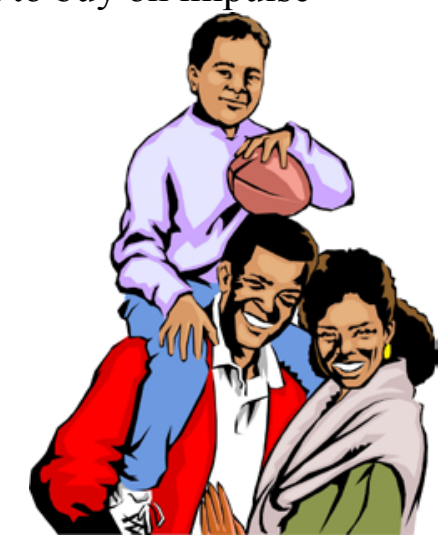
family's opportunities and bring financial and economic success. It also encourages family solidarity.

Be sure to look over your plan from time to time. Keeping records will make it possible for you to fit your resources to your goals. Tracking net worth and surplus or deficit can be helpful as they summarize financial position. If you will spend a few minutes each month looking over your spending, you can stop any bad habits before a financial disaster occurs. Then, once or twice a year, check over the whole picture to see what has helped or hurt you in reaching your family's goals.

Your spending plan is the key to your family's activities in buying, borrowing, saving, investing, purchasing a home, paying debts and planning for the future. Operating without some kind of budget is like trying to drive a car without a steering wheel. Develop a systematic plan for using available money to get as many of the things you want as possible. Stick to that plan closely when you are spending your income and you will reach your goals! That is what money management is all about. For your own happiness, start your plan today.

Continue to read and develop your money management skills. Several other fact sheets are available in this series. If you are interested in more information on a spending plan, call or write to your County Extension Family and Consumer Sciences Agent, who can help you with your budget planning and family economics. 